directed downwards and backwards must give an impetus upwards and forwards; the still surface so directed will glide downwards and forwards. I do not deny that if the down stroke of the bird's wing be directed backwards, beyond a certain angle, the resultant motion will be, as $\mathrm{Mr}$. Wallace says, "obliquely downwards." But why? Because all the sustaining forces above enumerated are so seriously diminished-the horizontal and forward forces, with the exception of $(d)$, being increased-that, to use Mr. Wallace's words,. "the surplus vertical reaction of the down stroke over the up stroke is no longer able to overcome gravity," which converts the bird's wings for the nonce into kites as it comes sailing downwards, making but an occasional strike, now that the horizontal effect of the wings is so great, to increase the obliquity of its descent.

But within the limits of this angle, whatever they be, the effect of a downward and backward blow must, on mechanical grounds, be in general such as I have said. For clearness' sake it may not be superfluous to note an ambiguity in the expressions "downwards and backwards," "downwards and forwards;" they may apply either to the direction of the surface of the wing or to the direction of the anterior margin. I maintain only that the direction of the surface--in some wings, merely that of the anterior portion of the surface-is downwards and backwards. The anterior margin, by the contraction of the great pectoral muscle, is drawn downwards and forwards, in which, by the way, there is the further advantage that less air will escape from under the wing in front.

But, secondly, what can we observe as to the down stroke? (I) A fact, pointed out to me by an anatomical friend - that the great pectoral muscle which depresses the wing is inserted into a crest situated on the upper and forward side of the head of the humerus, so as to tilt the under surface of the wing slightly upwards, i.e. give it a backward direction. (2) If the flight of rooks, or still better of pigeons, be watched from a window towards sumset, the position of the shadows on the under side of the wings will be found pretty conclusive as to their direction. (3) The forward inclination of the wings of a bird about to alight, which shows that the motion of the wings in such a position retards flight. (4) The action of heavy land or water birds, that have to attain some momentum by the use of both feet and wings before they can rise; here surely a forward blow against the air is manifestly absurd. (5) "The highly-inclined position of a hovering bird," noticed by Mr. Wallace, and not of the bird only, but of his wings.

Mr. Wallace's closing remark is both true and sound:- "A bird's wing is a highly complex apparatus, subject to a variety of flexures and motions in every feather." Still it is possible, even probable, that all this variety is referrible to a few simple principles. It is with these alone that I have ventured to concern myself.

Trin. Coll., Camb., March 3

JAMES WARD

With reference to Dr. Pettigrew's letter in NATuRE, vol. ix. p. 362 , I cannot do better than ask him to read the two papers that I refer to in my former reply, which he has evidently not done.

March 16

A. H. GARROD

The Moon's Want of Atmosphere

Your very suggestive review of Messrs. Nasmyth and Carpenter's work on "The Moon "leads me to propose an explana. tion of the absence of a lunar atmosphere, which I do not remember to have seen anywhere. The many arguments in favour of the temperature of the lunar surface being near or at the absolute zero, when added to the equally probable supposition that at the absolute zero all matter assumes the solid form, makes nothing more probable in my mind than that it is the consolidation from cold of all the previously existing gases and vapours of the Moon which has caused its atmosphere to disappear. Prof. Frankland's theory of the frozen condition of the lunar surface is evidently different from the above, and Lord Rosse's observations on lunar radiation apply only to the direct reflection of the solar rays.

A. H. Garrod

\section{On Volcanic Eruptions}

A PASSAGE in Nasmyth's work on the "Moon" suggests, as a consequence, an explanation of volcanic eruptions that I have often given in lectures. The point to be explained is, why they are sudden and intermittent. Processes of cooling and expansion are gradual.
I postulate (I) that a solid crust is shrinking as it cools ; (2) that the liquid interior expands on solidifying; (3) that the melting-point of lava is lowered by pressure.

Let us start with a volcanic vent in which the aperture has become partially stopped by cooled or solidified ava. In the region below, pressure sets in from the cooling and ultimate solidification of part of the liquid mass. Hence the meltingpoint of the rest is lowered by (3). The process continues unti the pressure becomes sufficient to relieve itself through some vent, old or new; a lava rises in the vent. But this relieves the pressure, and it follows from (3) that more rock will solidify, suddenly, and in so doing force liquid rock rapidly up the vent.

A volcano is, in fact, a geyser of lava.

I do not remember to have seen this in any book; and it perhaps would have been hazardous to assert postulate (2) as certainly true previous to Nasmyth's experiments ; but I have thought it probable : and if it is true, postulate (3) follows, I believe, from the laws of heat, and the explanation will be sound. I shall be glad to hear what is thought of it by autho. ities.

Rugby, March I $_{3}$

J. M. WILSON

\section{Remarks on Ozone}

HAVING perused Dr. Moffatt's interesting communication on Ozone in the Scottish Meteorological Fournal of October last, and also noticed the paragraph on the subject in the Medical Times drawing attention to it, I beg to send the following remarks respecting some points in it open to criticism from outsiders :-

I. The numbers, and special years of records, are not stated in the statistical tables, which might be of importance for comparison with other persons' records.

2. The occurrence of ozone with hail, and not with snow, may be explained by its happening in warmer weather, and not in winter, and in the warmer stratum of air through which the hail falls from the cold stratum above.

3. The larger quantity of ozone in Table II. in winter over that in summer is anomalous, and inconsistent apparently with the records in Tables VI. and VII., where it is stated to increase with the temperature.

4. If ozone be thought to increase in quantity with increase of elevation above the level of the sea, it may be asked how that is to be reconciled with the greater prevalence of it at the sea-shore than inland.

5. If there be only an apparent connection between electrical storms and ozone, explanation may be required to account for the production of artificial ozone by electrical action, and whether the two be identical in constitution if not in origin.

6. The paragraph- "The air is drier near the tropics than about the equator," might be more clearly defined by adding the "tropical circles of cancer and capricorn," as within those lines it certainly gradually gets more and more humid.

7. In one paragraph there is stated to be an intimate con. nection between humidity of the atmosphere and the manifestation of ozone, and in another this is stated to be purely accidental, which is ambiguous, while the testimony in support of it is not in accord with that in Tables IX, and X., where the adverse record is apparent.

8. That the absolute humidity of the air diminishes with in. crease of elevation may be true in the case of lofty balloon ascents, away from any terrestrial influences of mountains, but, as pointed out in a note, the relative humidity increases, as we may see in Westmoreland or Dartmoor, where the heights are always misty and damp.

9. The tropical or trade roinds only chance to be land winds in some such regions as the North Indian Ocean, whereas they are generally said to be sea-breezes, as in the South Atlantic Ocean, in the ordinary acceptation of the term.

IO. The connection of the production of ozone by the means of turpentine will bring to the mind of the tourist the freshness of the air of hills planted with pine forests.

II. Accepting the theory that ozone is connected with the equatorial winds, it may be asked how the increase of ozone in the calm belts is to be accounted for, where there are only Polar winds, converging to ascend into the upper regions of the air from north and south.

12. The table of observations at sec on board ship would re. quire to be supplemented by a note of the period of the year and number of days on record, as the quantity of ozone is al. ready stated to vary with the seasons of the year (Table II.), and 